Journal of the

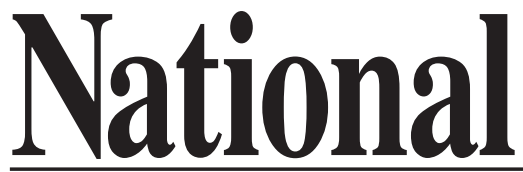

Academy or

Forensic
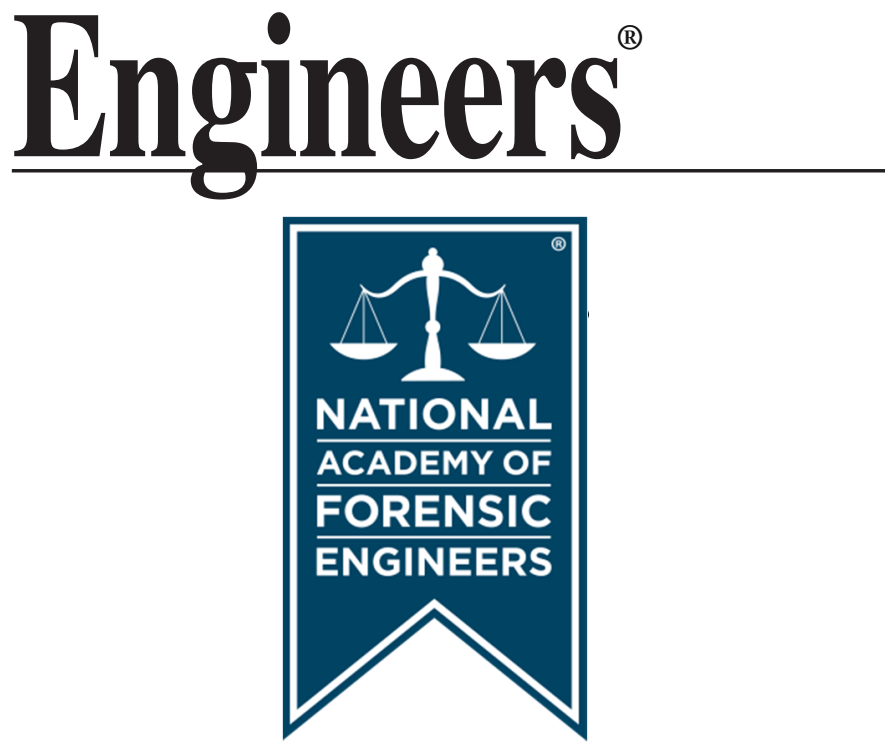

http://www.nafe.org ISSN: 2379-3252 


\title{
Forensic Engineering Investigation of Freeze Damage to Buildings
}

by John P. Certuse P.E. (NAFE 708F)

\begin{abstract}
The cause of property damage to buildings in northern climates due to frozen/burst pipes can be especially difficult to identify. The reasons for this include the lack of witnesses in vacant or unoccupied homes, false or misleading statements by property owners and service technicians, and the inherent damage to boilers and furnaces as a result of flooded basements.
\end{abstract}

The basic origins of freeze losses will be discussed including: mechanical failure, piping and appliance installation errors, utility failure, and excessive thermostat setback.

The methodology presented details a comprehensive approach to the investigation of freeze-damaged buildings, including a forensic assessment of the heating appliance and system. These findings will be verified against a fuel usage analysis calculated specifically for the damaged property, which should display a usage pattern consistent with the physical site findings and occupant reported testimony.

The methodologies of fuel usage estimation and analysis derived, as well as those presented in ASHRAE and other sources, will be discussed, along with their strength as an investigative tool in examining these types of losses.

Case examples will be briefly summarized that were actually litigated.

\section{Keywords List}

Forensic Engineering, Heating System Failure, Frozen Pipes, Excessive Thermostat Setback, Fuel Usage Analysis, Energy Analysis, K Factor, Burn Rate, Plumbing Installation Error, Improper Insulation, Freeze Protection, Failure to Maintain Heat

\section{Background}

Buildings located in northern climates rely upon the consistent operation of a heating system through winter months to maintain an acceptable temperature within the building envelope. Freezing of piping systems and the result- 
ing damage to buildings occurs in all types of dwellings; however, it is especially prevalent in ones that are unoccupied, either due to being seasonal, a.k.a. vacation homes, or properties for sale on the real estate market.

Freeze damage to homes in The United States is second only to hurricane damage with an estimated cost of over 4 billion dollars between 1995 and $2005 .^{1}$

In addition to water damage to interior finishes and contents, mold formation is also a byproduct of leaking pipes, which can pose a health concern to the occupants.

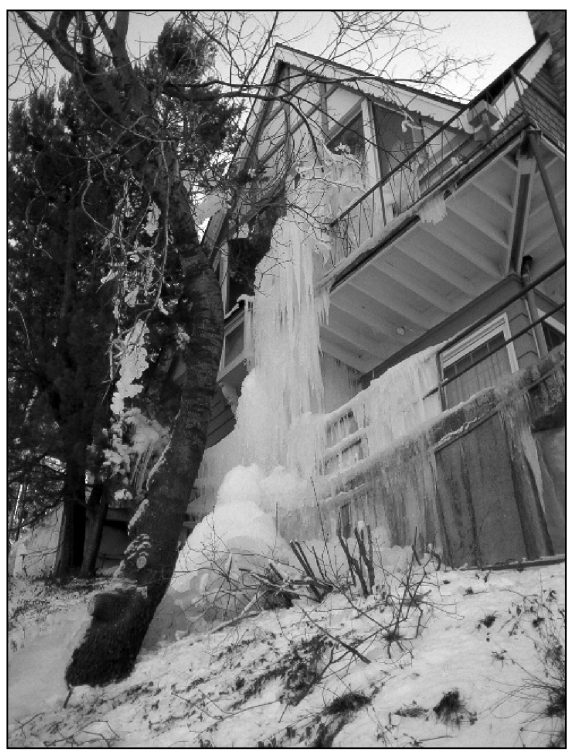

Occasionally, homes that are primary residences suffer damage caused by frozen pipes; however, this usually coincides with occupants being away for an extended period of time.

\section{Winterization Practices}

In the past, unoccupied homes were "winterized" by having piping systems either drained or protected with antifreeze and the building allowed to remain unheated through winter months.

With the recent choices and quality of construction materials, the use of marble, granite, and other materials prevent this former practice of shutting off a heating system during winter months. Cold temperatures will cause contraction in many of these materials, resulting in cracks and warping. Additionally, condensation can occur in building areas not being heated, allowing moisture buildup to occur.

\section{Identifying The Cause}

Since freeze damage to homes usually occurs when the homes are vacant as well as there being a constantly changing scenario of reported events and personnel involved with the loss, the true cause of these events can be very elusive.

Proper investigation of these types of losses requires an in-depth working knowledge of the heating appliance, proper piping installation and insulation 
techniques as well as building practices of residential and commercial structures. Additionally the application of engineering fundamentals such as fuel consumption, heat transfer, fluid mechanics, strength of materials and material properties provide the Forensic Engineer with the tools necessary for an accurate identification of the cause of the damages.

The many hats the Forensic Engineer will wear in the investigation of these losses will range from that of an engineer to that of a detective, requiring him to investigate claims of electrical utility outages, break-ins and vandalism all of which may be blamed for causing the loss.

\section{Initial Contact with property owners}

The first step in identifying the cause of the loss is to establish the parameters of the buildings occupancy.

Vital dates such as when someone was at the property prior to the loss, the loss date as well as who discovered the loss and what their findings and actions were are all required to establish the baseline of the investigation.

Often times, when investigating the origin of a freezeup loss, the information provided to the investigator is not accurate.

Reasons for this may be innocent and understandable due to the panic that ensues upon the discovery of this type of damage. Initial reactions to discovering this type of loss may result in actions such as the changing of thermostat settings and manipulation of service switches that may be forgotten later on.

Many insurance policies require that a homeowner maintain heat in a property. If the property owner suspects that he or she may be found to be negligent in this responsibility, they may be reluctant to provide detailed information leading to a coverage decision unfavorable to them.

Service personnel also may not be forthcoming with observations as to why the heating system had failed. In the event of the cause of a freeze loss being identified as a service negligence condition, evidence may be created after the fact and service documentation destroyed in an effort to discourage inquiries into their actions.

Identification of the cause of failure in freeze damaged buildings can be especially challenging, requiring the engineer to not only have a thorough working knowledge of the mechanical operation of the equipment but also be able to act as an investigator looking into other causes that may have contributed to the loss. 
Copyright @ National Academy of Forensic Engineers (NAFE) http://www.nafe.org. Redistribution or resale is illegal. Originally published in the Journal of the NAFE volume indicated on the cover page. ISSN: 2379-3252

\section{Four Root Causes of a Freezeup Loss}

Freeze damage to buildings can be identified as originating from one or any combination of the four following origins.

\begin{tabular}{|l|l|l|}
$\begin{array}{l}\text { Mechanical or Building } \\
\text { Electrical Failure }\end{array}$ & \multicolumn{2}{|c|}{$\begin{array}{l}\text { Mechanical } \\
\text { Breakdown } \\
\text { Installity and } \\
\text { Fof piping or applivery } \\
\text { ances) } \\
\begin{array}{l}\text { Utility or Fuel Delivery } \\
\text { Failure }\end{array}\end{array}$} \\
$\begin{array}{l}\text { Excessive Thermostat } \\
\text { Reduction }\end{array}$ & $\begin{array}{l}\text { Thermostat } \\
\text { Settings and } \\
\text { Maintaining Heat }\end{array}$ & $\begin{array}{l}\text { Installation } \\
\text { errors of } \\
\text { piping }\end{array}$ \\
\hline
\end{tabular}

\section{Mechanical and Electrical System Failure of Equipment}

Mechanical breakdown of equipment is simply the shutdown of a heating system due to any mechanical or electro mechanical component failure.

This includes anything from a broken part that would have rendered the system inoperable, a building electrical system failure to a service error or lack of service condition that contributed to the appliance shutting down.

In the event of a failed component or part, there may be a potential for subrogational pursuit against the manufacturer of this component.

Losses have been identified as being the result of failures in vital heating system components, such as electronic primary controls, circulating pumps, and other vital components of the heating system.

Another common mechanical failure could be the result of a service error.

In the event that an oil burner is not properly calibrated or a gas combustion train properly adjusted or cleaned, conditions could exist where the equipment will shutdown during winter months.

Boilers and furnaces contain safety controls designed to shut the unit down during an unsafe operating condition. Lack of or faulty service can often allow or create conditions where these safety controls shut the appliance down. 


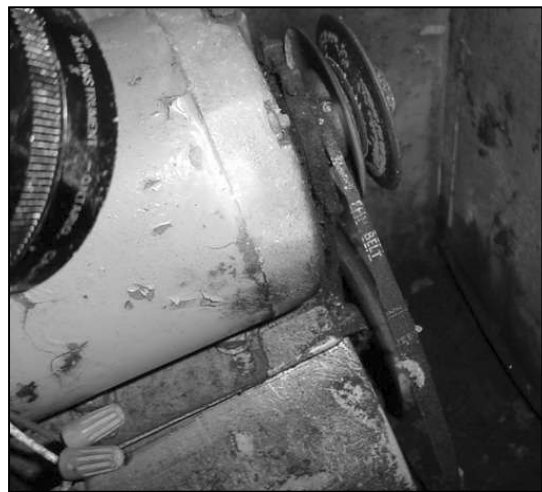

\section{Broken Fan Belt in Forced Hot Air Furnace}

In this photo, a freeze loss resulted due to a broken fan belt on a forced hot air furnace.

Checking of these components should be done during annual maintenance events.

Presently the details of specific insurance policies may vary from company to company however the term "failure to maintain heat" is often referred to when coverage is denied. Diligently maintaining heat in a dwelling varies in accordance with the building owners understanding of the term and is often the battleground of legal debates of these issues.

Although it is not known what percentage of insurance policies require annual maintenance of these systems, in order to prove to an insurer that they are "Maintaining Heat", annual service is a requirement of all heating systems and as such could theoretically be the basis of a coverage denial.

Service contracts should be obtained and examined and compared with the conditions found at the loss site to verify that the equipment was serviced in accordance with contractual obligations.

\section{Installation Errors in Piping and Appliances}

The second root cause of a heating system failure is identified as installation errors. Installation errors are applicable to both the appliance, as well as the piping within the building.

Most freeze damage to piping caused solely by where it is installed usually becomes evident during the first winter. Considering this, it appears that Charles Darwin's "Survival of the fittest" theory, as detailed in "The Origin of Species", not only applies to animals but to engineered structures and systems, as well, when facing mother nature.

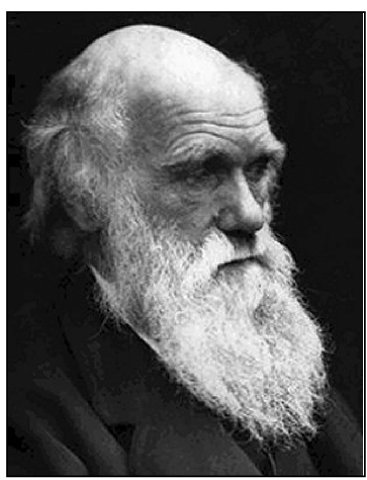

Charles Darwin 
Copyright $\odot$ National Academy of Forensic Engineers (NAFE) http://www.nafe.org. Redistribution or resale is illegal. Originally published in the Journal of the NAFE volume indicated on the cover page. ISSN: 2379-3252

The International Plumbing Code, as well as other state plumbing codes, differentiates between heating system piping (i.e. hydronic heating system piping) and piping that is part of the plumbing system.

\section{Domestic Water Plumbing}

Addressing the plumbing system, existing codes essentially require that pipes not be installed in a location prone to freezing unless it is protected from freezing by the use of insulation, the application of heat, or both.

These codes are void of any further detailed specifications telling plumbers how to do this, leaving the task of doing so to their own design.

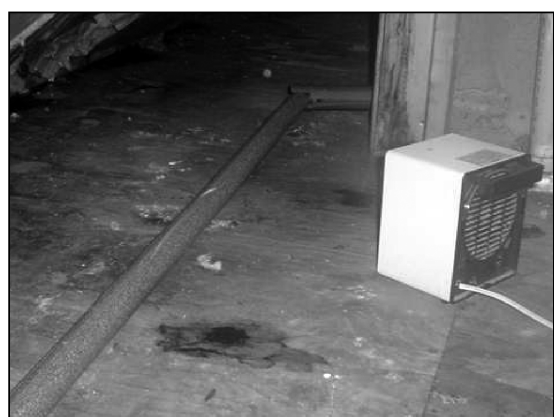

Here a domestic water pipe installed in an unheated attic is susceptible to freezing and in violation of all plumbing codes.

Locations of piping installations that are prone to freezing are usually in unheated voids within the building, such as crawl spaces exposed to outdoor air, adjacent to attic spaces, as well as outside walls, and in some cases, chaseways that have air leaks, allowing the infiltration of outside air into the building envelope, allowing contact with this piping.

As depicted in the following sketches, if a building's thermostat is set at the typical design temperature of 70 degrees, the inner boundary layer of air of the interior wall is being maintained at the thermostat setting. The interior of the wall however will become increasingly colder away from the interior even if it is properly insulated.

\section{Hydronic Water Piping}

Hydronic heating systems use water to transport heat from a boiler to the heat radiators, baseboards or heat exchangers located throughout the building.

Usually due to the goal of cost reduction, this fluid is water but occasionally especially in problem prone systems running in unheated areas, antifreeze may be added to protect these systems.

Hydronic heating system piping installation requirements are addressed in the International Mechanical, as well as the International Energy Conservation, Codes.

The International Energy Conservation Codes list requirements for insulation thickness of hydronic heating system piping passing through unheated spaces. 


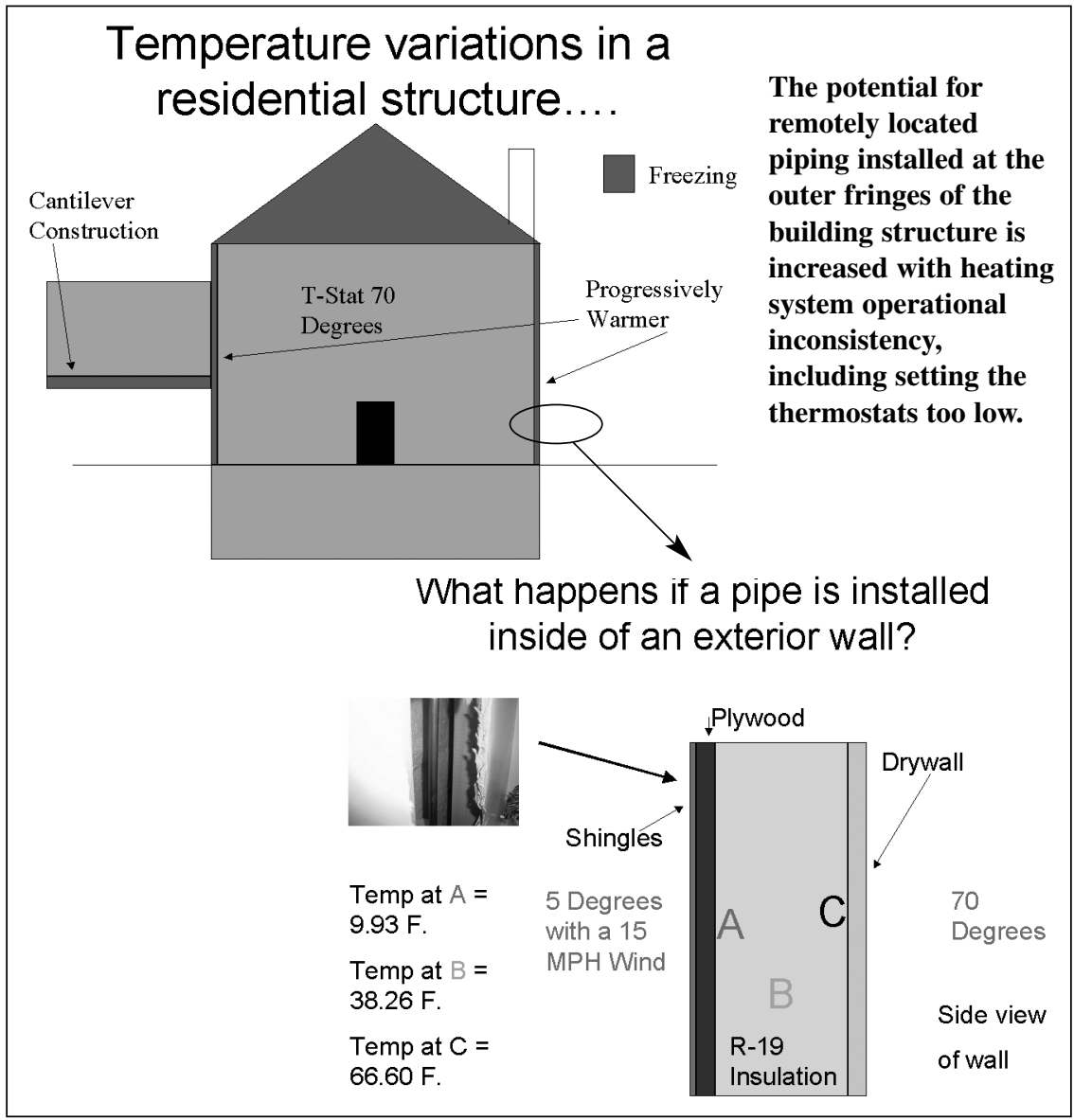

Although this requirement appears to be done with "energy conservation" in mind, the addition of insulation to heated, hydronic heating system piping will slow transfer of heat, helping to protect the pipe from freezing.

There are no specific references to protecting heating system piping from freezing in these codes; however, other guidelines, including the appliances installation instructions, may present ways to protect hydronic heating system piping from freezing.

\section{The Hydronics Institute division of GAMA's Residential Hydronic} Heating System Guide 2000 provides guidelines as to how hydronic heating system pipes should be installed, and in the event of being installed in locations prone to freezing directs the use of anti-freeze. 
Copyright ( National Academy of Forensic Engineers (NAFE) http://www.nafe.org. Redistribution or resale is illegal. Originally published in the Journal of the NAFE volume indicated on the cover page. ISSN: 2379-3252

\section{Installation Errors in Appliances}

\section{Installations in locations prone to freezing}

Boilers, water heaters, and air handlers with hot water coils (heat exchangers) should not be installed in areas prone to freezing, unless provisions to prevent freezing is made.

\section{Hydro Air Systems}

A common heating system installed in recent years is a forced hot air system that receives its heat

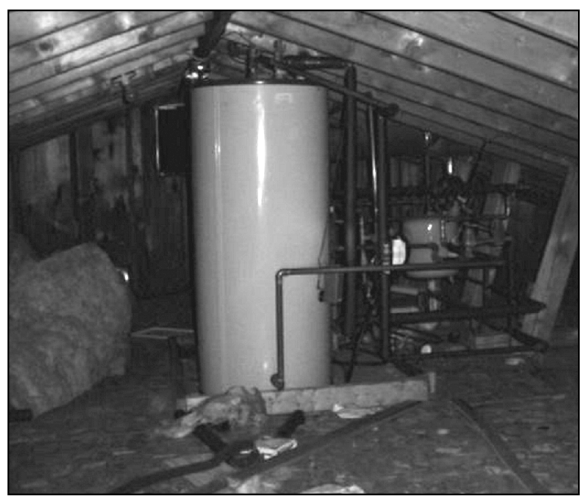

In this photo, a hot water heater as well as a boiler and all of their associated piping was installed in an unheated attic location. source from a central boiler that pumps its heated water to and from the air handler coil. This "Hydro Air" system is popular in that it also functions as an air conditioning system in summer months.

An inherent danger with this type of system, however, is that oftentimes air handlers servicing upper floors are

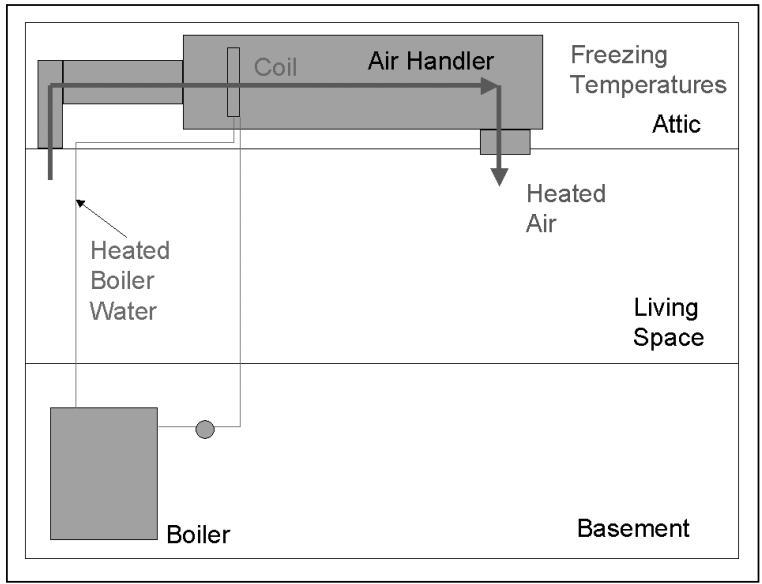
installed in unheated attics. When heat from lower floors satisfies upper floor thermostats, the attic unit runs less frequently and does not circulate boiler water, allowing freeze damage to occur.

Although experienced contractors know of this danger, not all manufacturers direct installers and service personnel to take measures against freezing of these systems.

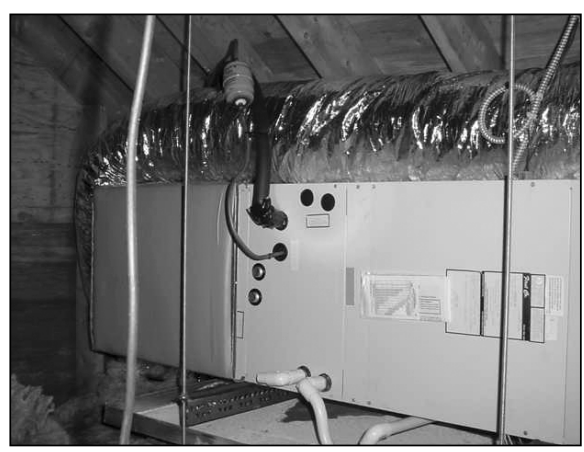

This air handler installed in a freezing attic was provided with warnings from the manufacturer as to installing it in this location. 
Copyright @ National Academy of Forensic Engineers (NAFE) http://www.nafe.org. Redistribution or resale is illegal. Originally published in the Journal of the NAFE volume indicated on the cover page. ISSN: 2379-3252

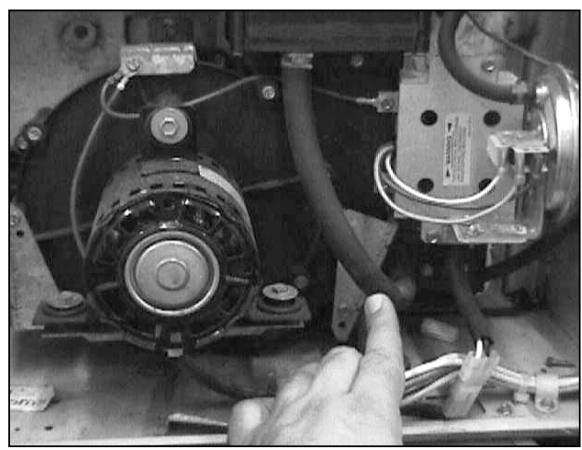

Condensing appliances that rely upon tubing to collect and drain accumulating condensate can shut down due to this condensate freezing and safety switches monitoring the flow of this condensate, shutting the appliance down.

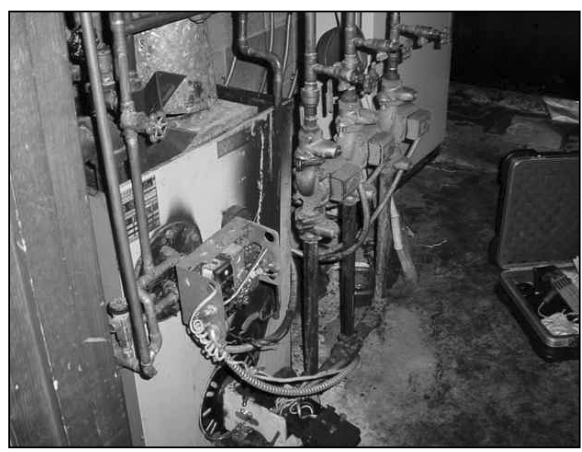

A boiler in a small room starves for combustion air.

\section{Condensing Appliances}

High efficiency boilers and furnaces that draw enough heat out of the products of combustion where there is condensation within the system should be carefully inspected to identify if they have been certified for installation in a location prone to freezing.

\section{Confined Spaces of Installation}

Confined spaces of installation for combustion equipment can cause a heating system appliance to "starve" for combustion air, which in turn can produce soot, which can clog the firesides of these appliances, leading to equipment shutdown.

Care should be taken to identify if appliances are installed in a location that would contribute to their shutdown during winter months.

Installation manuals provide information regarding if the appliance is rated for installation in certain locations - such as spaces capable of having freezing temperatures and small rooms with limited

combustion air, known as confined spaces of installation.

As per the 2002 NFPA 54 Chapter 8.3.2.1, the input BTU per hour air requirement for combustion appliances indicates that for every thousand BTUs per hour of input that an appliance delivers, 50 cubic feet of air shall be available, if the appliance is drawing from the same room where it is installed.

NFPA 31, as well as NFPA 54 and other codes, details ways to supply air to appliances that would have been otherwise installed in rooms too small to provide boilers and furnaces with an uninterrupted supply of fresh combustion air.

These include mechanical draft air delivery ventilators and ductwork systems. 
Copyright () National Academy of Forensic Engineers (NAFE) http://www.nafe.org. Redistribution or resale is illegal. Originally published in the Journal of the NAFE volume indicated on the cover page. ISSN: 2379-3252

\section{Utility/Fuel Delivery Failure}

The third basic origin of freeze damage to buildings is the result of a utility or fuel delivery failure.

In the event of an electrical outage, heating systems become inoperable, and depending upon the length of the electrical outage may be shut down long enough to cause the temperatures to fall to a point where the piping within the building envelope will freeze.

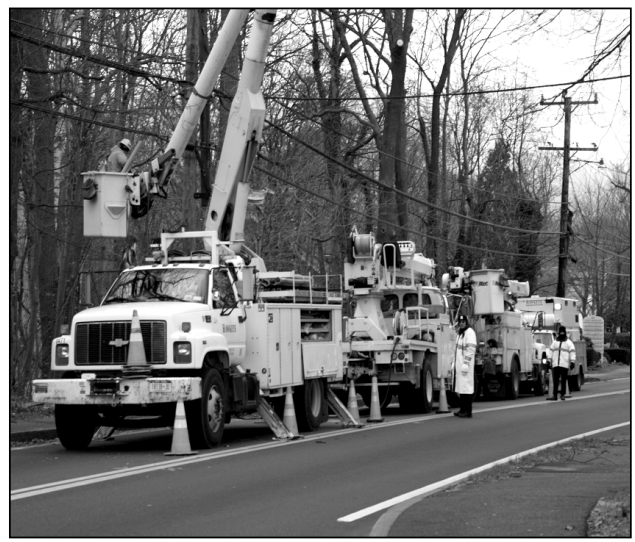

Many electrical companies will identify through their service department if there was an electrical outage in a neighborhood where a loss had occurred, if asked.

\section{Late Fuel Delivery (Heating Oil, Propane)}

Fuel tank run outs are another common cause of freeze damage to buildings.

Care should be taken to identify if fuel is being delivered under an automatic delivery program.

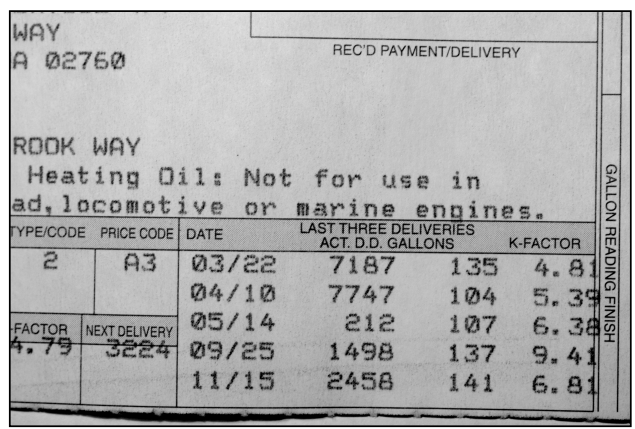

These same suppliers rely upon a delivery schedule based upon the accumulated Heating Degree Days (HDD) in their service area.

Each house is identified with it's own "K Factor" unit of fuel consumption which is in units of HDD/Gallon of fuel delivered.

There are no laws, rules or requirements for suppliers to maintain their customers fuel tank levels at certain quantities other than indicated in individual contracts between the customer and supplier.

If the obligations of the delivery agreement required by the customer are met (such as building additions or alternate heating sources being used are reported to the fuel supplier) the fuel company should be able to predict tank quantities and make a timely delivery prior to the tank's fuel level expiring. 
The possibility of contaminated fuel should be considered as a cause of heating system shutdown as well. Fuel samples can be taken and analyzed during the investigation for this possibility. Various laboratories are available to provide detailed analyses of contaminates of suspect tanks.

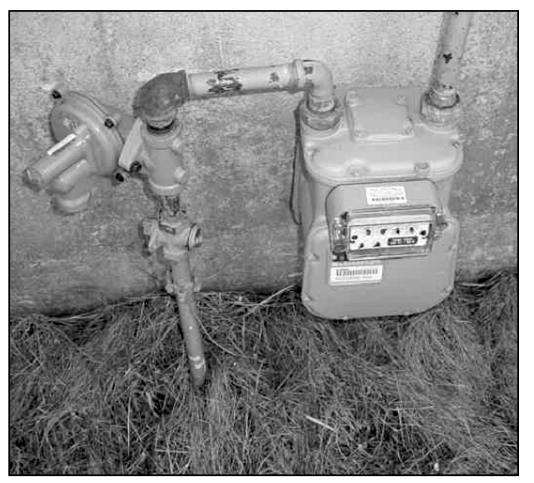

\section{Natural Gas}

A third utility failure that should also be considered is the possibility of a gas flow interruption. Natural gas, which contrary to tank based fuel sources, is supplied to various homes through a network of piping in the community where they are placed.

Although rare, there have been instances where there have been reports of gas shortages possibly contributing to freeze damage in buildings.

\section{Phone System Failure}

Finally, although not an originator of freeze damage to a building, in the event of a telephone line failure, cold temperature alarms that may alert someone to the event of a cold temperature within a home can contribute to the damage at the property by failing to contact someone in the event of freeze damage.

In homes that are outfitted with a cold temperature alarm, the possibility of a telephone line failure coinciding with freeze damage, as well as the condition of the phone system within the building, should be investigated and addressed as well.

Likewise, the alarm itself should be tested to identify if it is operating properly and the root cause of that failure should be identified.

\section{Excessive Thermostat Setback}

One of the more common causes of heating system failures is the result of the occupants turning the thermostats too low.

Excessive thermostat setback can cause damage to properties causing the temperatures at the outlying portions of the building to fall exponentially lower, as well. If there is piping installed in these outlying areas, this piping will be exposed to freezing temperatures. 
Copyright @ National Academy of Forensic Engineers (NAFE) http://www.nafe.org. Redistribution or resale is illegal. Originally published in the Journal of the NAFE volume indicated on the cover page. ISSN: 2379-3252

Fuel conservation measures have trained the public to turn down their thermostats however this is often done without regard for the threshold of where a thermostat setting fails to effectively heat a house in cold weather.

Each home will also be different in its ability to withstand a colder thermostat setting due to where and how within that building the piping is installed.

Also, in the event of a heating system failure, a house maintained at 60 degrees will maintain temperatures above freezing for a longer period of time than a house that has its temperature maintained at a lower temperature.

\section{Thermostat Placement}

Depending upon where a thermostat is placed within a building structure, if the thermostat is not representative of the temperature where piping may be installed, temperature differences as much as 25 degrees can result.

Turning a thermostat down to a temperature of 50 degrees may be allowable in some homes, since each home is unique upon itself; however the degree to which the thermostat can be turned down will change from building to building.

There are no published "minimum tem-

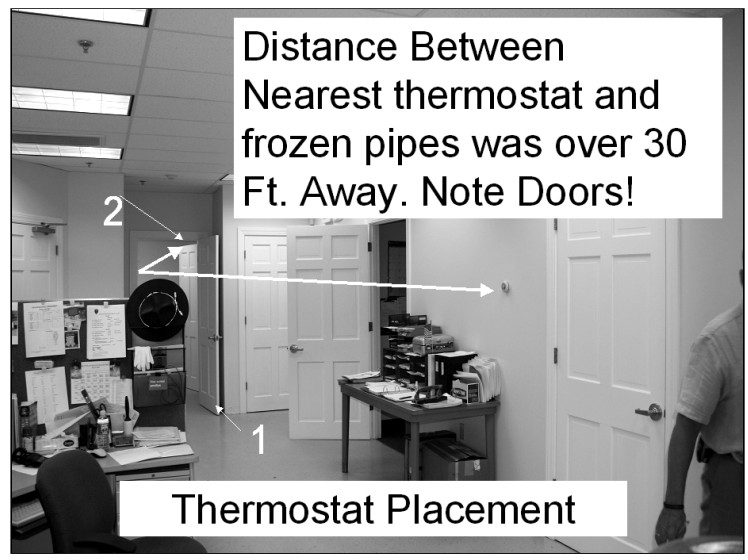
perature setting requirements" known to exist to protect a home in winter months. The lack of guidance in this area has been the fodder of many legal battles regarding coverage for homes damaged by freezing when excessive thermostat setback is identified as the sole or contributing cause of the loss.

\section{Interaction Between Four Root Causes}

Although a mechanical failure, installation error, utility/fuel delivery failure, or excessive thermostat setback condition can individually cause freeze damage to a property, each of the four root causes of a freezeup loss can also play off of each other, as well.

This interaction between the root causes is exemplified in conditions such as there being a pipe installed in an outside wall that, in the event of the home being heated to the 65 degree range, would be adequately heated. However, in the event 
of the thermostat being turned below 55 degrees, this may result in a corresponding temperature in this outside wall exposing this pipe to freezing temperatures.

It is for this reason that a comprehensive approach to heating system failure analysis is essential, as well as the need to verify any field observation or statement through an independent analysis of the fuel usage at this property.

\section{FORENSIC ENGINEERING OBSERVATIONS IN THE FIELD}

\section{The First Responder/ Interview}

When investigating freeze damage to a building, the site examination should start with an interview of the person or persons who first discovered the loss and then any service technicians who made any repairs.

Vital information should be identified, such as when someone was last at the property prior to the discovery, the date of discovery, visual observations of how the equipment was functioning, i.e. was a blower fan operational or were any switches turned off or on during the discovery of the loss?

Service technicians should also be interviewed (if possible) as to what observations or repairs they made, if at all. It must be understood that information provided during these initial interviews may not be accurate based upon concerns that these individuals may have regarding their liability in the loss.

When examining equipment in the field, it is important to establish a baseline as to how the heating system was configured at the time of loss. It should be realized that there may be some slight changes made by any first responders to the loss.

\section{General Observations}

Electrical switch positions of any emergency or service switches on the boiler or furnace should be noted to determine if the equipment was simply shut off. Many times, these switches that resemble a simple light switch may have been mistaken as being a light switch and turned into the off position.

Many gas fired equipments have a mechanical damper that opens when the heating system is calling for heat and closes when the temperatures within the building are satisfied. In the event of a sudden shutdown, the damper, itself, will stay in the position that it was at the time of the loss.

In the event that a damper is in a closed position, it indicates that the appliance was not "calling for heat" at the time of power interruption to the property. It is important to know the actual operating characteristics of the particular 
Copyright @ National Academy of Forensic Engineers (NAFE) http://www.nafe.org. Redistribution or resale is illegal. Originally published in the Journal of the NAFE volume indicated on the cover page. ISSN: 2379-3252

PAGE 56

JUNE 2008

NAFE 708F

damper in question to verify the default operation of it in the event of a power outage.

The location of thermostats and thermostat settings should also be noted during this initial observation of the site.

Many times, freeze damage to piping occurs as a result of a thermostat being lowered and then being separated from the point of freeze damage to the piping within the building by excessive distance or doors that were closed preventing the thermostat from identifying the representative temperature within the space where they were enclosed.

\section{Flood Damaged Equipment}

As is often the case, freeze damage to piping within a building can cause massive floods, which many times flood the basement where boilers and furnaces are usually placed.

Although a boiler or furnace may have been submerged under water, valuable data can still be gathered by observing the condition of the appliance and careful testing of many of its components.

Gas fired equipment, if firing while being flooded with water, will oftentimes exhibit a characteristic known as rollout, due to the encroaching water in the gas burner bars.
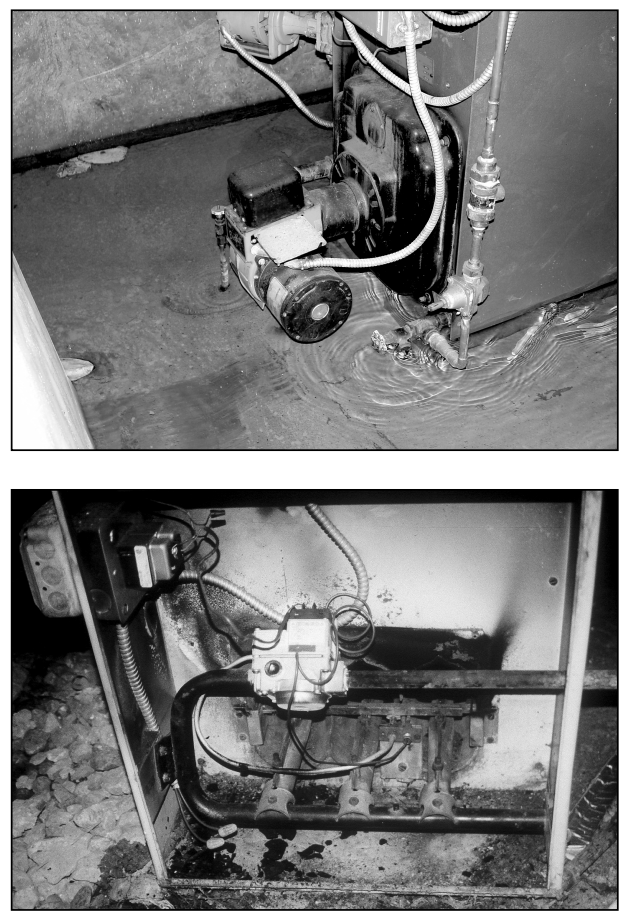

This characteristic water flooding rollout indicates that the appliance was calling for heat while a leaking pipe in the home was submerging the appliance.

Rollout is a condition where the products of combustion back out of the combustion chamber resulting in fire damage to the outside of the appliance. This indicates that the gas burner components of the furnace, be it the gas valve, thermo couple, or other components, were operational at the time of the encroaching floodwaters. 
Many electric motors, even though they have been submerged, can also provide valuable information, as well.

Motors for hydronic heating system circulator pumps, as well as forced hot air furnace blowers, can be evaluated by first observing for simple conditions such as a broken fan belt or seizure of the motor pump/fan.

Many electrical motors, even if submerged, can still be energized and may operate indicating that they were operational at the time of encroaching floodwaters.

Oil burners that have been submerged in water can be examined to see if the burner ran out of fuel prior to the loss.

In the event of an oil tank running out of fuel, the oil line between the tank and the oil burner will become filled with air, which must be bled from the line (a process known as priming) before an oil burner can be returned back into operation.

In the event that the oil tank has run out of oil, causing the burner to shut down, if oil is delivered immediately after this, by removing the electrical components that have been damaged from the oil burner and while preserving the integrity of the fuel pump, jet line, oil burner nozzle and fuel line, the oil burner can be re-energized and the "time of loss" fuel condition of the oil burner can be identified to verify if it ran out of fuel or not.

\section{The Properties of Ice Expansion}

The volume of ice is $10 \%$ greater than the water from which it is formed. Pressures in excess of 17,000 Lbs/Square Inch have been measured as a result of expanding ice in a closed system. Additionally, in the event of ice formation in a closed system, the entire piping system does not need to be frozen in order to induce excessive pressures. In the event that a portion of the system has frozen, this volume change can be transmitted to the "non frozen" portion of the system inducing pressure induced failures in the piping and components.

Fracture features of freeze damaged piping and fixtures includes longitudinal fractures, expansion and bulging, fittings being forced off in numerous locations especially in PEX types of piping systems and solder joints being separated in copper piping systems.

Finally to aid in a timeline as to when freeze damage has occurred, it is true that hot water will freeze before cold water piping. This is reportedly due to the Mpemba effect which is affected by evaporation, dissolved gasses, convection and the surroundings in hot water systems. 
Copyright @ National Academy of Forensic Engineers (NAFE) http://www.nafe.org. Redistribution or resale is illegal. Originally published in the Journal of the NAFE volume indicated on the cover page. ISSN: 2379-3252

\section{Piping Observations}

The location and number of piping breaks in a structure can also provide useful forensic engineering information regarding why the heating system had shut down.

A large number of plumbing breaks present throughout the building structure is an indication that the heating system itself had shut down and stayed shut down for an extended period of time.

Localized plumbing breaks, i.e. one in a pipe that is installed in an attic/eave area or in an outside wall, is usually indicative of a condition such as excessive thermostat setback or indicates that a heating system has been shut down for a short period of time.

\section{FUEL (ENERGY) USAGE ANALYSIS AS AN INVESTIGATIVE TOOL}

Mechanical shutdown, installation error, utility failure, and excessive thermostat setback are the identified root causes of a heating system failure.

These causes, however, are reliant upon the physical equipment and piping observations, as well as reported testimony from persons with interests, which may not include the identification of an actual cause of loss.

Energy usage analysis (electricity, natural gas, propane, oil, wood, or other energy source) provides an independent check in verifying if the believed cause of system failure is true.

Although heating engineers routinely calculate the heating requirements of a new building based upon the estimated heat transfer performance of the building envelope, it is only after this building is built that the actual performance can be identified.

\section{Fuel Estimation Calculation Origins}

Audel's 1946 "Oil Burner Guide" By Frank D. Graham sets forth the following guideline as far as fuel usage in a residential structure:

\section{PERCENTAGE OF YEARLY FUEL USAGE}

September $1.4 \%$

October $6.6 \%$

November $11.5 \%$

December $17 \%$
January $18.5 \%$

February $17.0 \%$

March $15.0 \%$

April $8.0 \%$ 
Copyright $\odot$ National Academy of Forensic Engineers (NAFE) http://www.nafe.org. Redistribution or resale is illegal.

Originally published in the Journal of the NAFE volume indicated on the cover page. ISSN: 2379-3252

NAFE 708F

FREEZE DAMAGE TO BUILDINGS

PAGE 59

Later, Consumption or Heating Degree Day (HDD) methods were developed to be used in fuel delivery estimations and computer programs.

The American Society of Heating Refrigeration and Air Conditioning Engineers ASHRAE's Fundamental Handbook details various energy consumption calculation methods. One version described by ASHRAE's "Steady State" method in use in the heating industry today is the Heating Degree Day or Consumption Method.

\section{Fuel Delivery Programs Used By Fuel Delivery Companies}

Fuel delivery programs that have been written for the heating industry are based upon ASHRAE's defined "Steady State" assumption that the temperature in a building will be held in the 65 to 70 degree range. The amount of fuel consumed in a particular building is correlated against the "need for heat" of the building's geographical area i.e. the Heating Degree Day (HDD) and a ratio for each delivery is obtained.

The "need for heat" in a home is identified by the value derived for the heating industry known as a heating degree day. This daily value is provided by NOAA, (the National Oceanic and Atmospheric Administration) and other weather data providers. A heating degree-day is calculated as the average temperature within a 24-hour period subtracted from 65 . I have encountered a company that relied on the HDD value from the local newspaper while other companies have used other means to obtain this data.

The heating industry also uses other means to obtain accurate heating degree day values for the areas they service including the Hidy-Brown Recorder System and weather stations on the property of the oil company recording daily readings.

Essentially, how fuel delivery programs work for companies that deliver LP gas or oil to a fuel tank is by measuring the amount of fuel delivered between delivery dates during winter months and identifying the total amount of accumulated heating degree days. This ("Heating Degree Day (HDD) / Unit of Fuel) Unit is known as the "K Factor".

These types of systems have been in use for many years and have provided a reliable method that fuel delivery companies can use to schedule their fuel deliveries. As long as the home is heated in a consistent manner using the central heating system and its primary fuel source while not relying on alternate sources of heat (wood burning stoves, fireplaces etc.) this system has been demonstrated as being reliable. Additionally, by using a fuel delivery program, deliveries can be scheduled according to customer's own particular burn rate and 
Copyright ( ) National Academy of Forensic Engineers (NAFE) http://www.nafe.org. Redistribution or resale is illegal. Originally published in the Journal of the NAFE volume indicated on the cover page. ISSN: 2379-3252

PAGE 60

JUNE 2008

NAFE 708F

tank size requiring that only customers needing fuel on a given date be serviced minimizing travel and delivery times.

\section{Modifying the Fuel Delivery Program Into An Investigative Tool}

By analyzing trends in fuel consumption in a similar manner to that which the heating industry uses to schedule their deliveries, changes in the heating practice of a building can be identified. These changes can be analyzed to determine if they coincide with field observations and reported testimony of people involved or to identify disputes in reported testimony.

Whenever a freezeup loss is being investigated, fuel records should be provided for at least twelve to twenty-four months prior to the loss so that one or more winter periods of heating consumption can be analyzed. Contrarily, if fuel records are not able to be obtained prior to the loss, the fuel consumption after the loss can also be used to identify the building's burn rate.

These fuel delivery amounts can then be analyzed in relation to accumulated heating degree days to identify either the k-factor (heating degree days per unit of fuel delivered) or the reciprocal of this number, the "burn rate" in units of fuel consumed per heating degree day for the property.

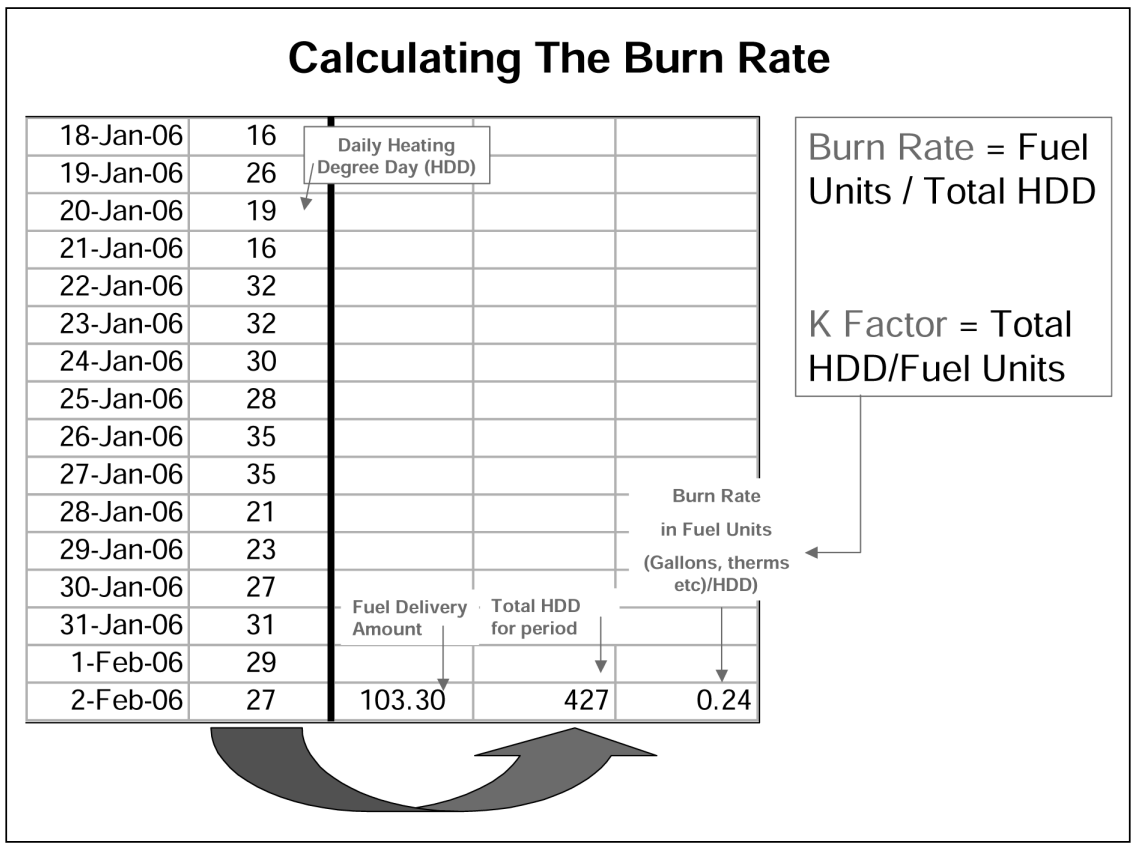


Copyright $\odot$ National Academy of Forensic Engineers (NAFE) http://www.nafe.org. Redistribution or resale is illegal. Originally published in the Journal of the NAFE volume indicated on the cover page. ISSN: 2379-3252

In addition to the fuel records, if the system is still shut off after the loss, the most important fuel reading is an actual measurement of fuel in the LP or oil tanks or a gas meter reading. Oil tanks should be measured by inserting a clean $1 / 8$ inch dowel into each tank to measure the liquid level directly.

By graphing the burn rate, as opposed to the $\mathrm{K}$ Factor, a direct correlation with an orientation consistent with increases or decreases in fuel consumption can be plotted to graphically show the heating trends prior to and up to the date of loss of the building.

By dividing the amount of fuel consumed in a period of time by the total accumulated heating degree days (HDD) during this time, periodic burn rates can be identified. Changes in these burn rates and their corresponding meaning can be used to verify or dispute field findings and testimonial statements regarding the loss.

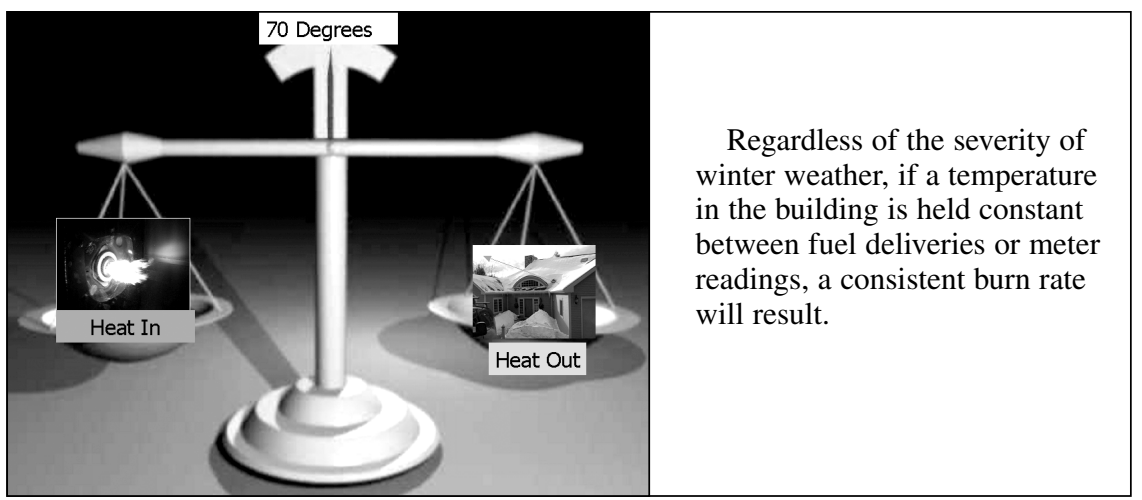


Copyright @ National Academy of Forensic Engineers (NAFE) http://www.nafe.org. Redistribution or resale is illegal. Originally published in the Journal of the NAFE volume indicated on the cover page. ISSN: 2379-3252

\begin{tabular}{|c|c|c|c|c|c|c|c|c|c|}
\hline \multicolumn{5}{|c|}{$\begin{array}{c}\text { November } \\
\text { Burn Rate Calculation }\end{array}$} & \multicolumn{5}{|c|}{$\begin{array}{c}\text { January } \\
\text { Burn Rate Calculation }\end{array}$} \\
\hline 3-Nov-05 & 13 & & & & 18-Jan-06 & 16 & & & \\
\hline 4-Nov-05 & 11 & & & & 19-Jan-06 & 26 & & & \\
\hline 5-Nov-05 & 10 & & & & 20-Jan-06 & 19 & & & \\
\hline 6-Nov-05 & 12 & & & & 21-Jan-06 & 16 & & & \\
\hline 7-Nov-05 & 11 & & & & 22-Jan-06 & 32 & & & \\
\hline 8-Nov-05 & 12 & & & & 23-Jan-06 & 32 & & & \\
\hline 9-Nov-05 & 17 & & & & 24-Jan-06 & 30 & & & \\
\hline 10-Nov-05 & 16 & & & & 25-Jan-06 & 28 & & & \\
\hline 11-Nov-05 & 26 & & & & 26-Jan-06 & 35 & & & \\
\hline 12-Nov-05 & 24 & & & & 27-Jan-06 & 35 & & & \\
\hline 13-Nov-05 & 13 & & & & 28-Jan-06 & 21 & & & \\
\hline 14-Nov-05 & 11 & & & & 29-Jan-06 & 23 & & & \\
\hline 15-Nov-05 & 20 & & & & $30-$ Jan-06 & 27 & & & \\
\hline 16-Nov-05 & 9 & & & & 31-Jan-06 & 31 & & & \\
\hline 17-Nov-05 & 22 & & & & 1-Feb-06 & 29 & & & \\
\hline 18-Nov-05 & 29 & & & & 2-Feb-06 & 27 & 103.30 & 427 & 0.24 \\
\hline 19-Nov-05 & 29 & & & & & & & & \\
\hline 20-Nov-05 & 19 & & & & & & & & \\
\hline 21-Nov-05 & 15 & & & & & & & & \\
\hline 22-Nov-05 & 22 & & & & & & & & \\
\hline 23-Nov-05 & 33 & & & & Adhering to & he & ed to $d$ & fue & ised \\
\hline 24-Nov-05 & 30 & & & & upon cumu & tive & eating & ee D & \\
\hline 25-Nov-05 & 38 & & & & (HDD), res & ts it & imilar o & ntic & urn \\
\hline 26-Nov-05 & 34 & & & & rates betw & en & I deliv & or $\mathrm{f}$ & \\
\hline 27-Nov-05 & $\frac{27}{19}$ & & & & meter reac & ags & & & \\
\hline $\begin{array}{l}\text { 28-Nov-05 } \\
\text { 29-Nov-05 }\end{array}$ & 12 & 129.00 & 534 & 0.24 & & & & & \\
\hline
\end{tabular}

Applying this fuel usage analysis to homes where the temperatures are known to be consistent results in a signature graph that shows flat plateaus throughout the winter months that coincide with the same burn rate consistently throughout subsequent winters.

Peaks of burn rates during "non heating" months should be ignored since this simply shows a fuel delivery in time periods where there was a low accumulation of heating degree-days resulting in this graph characteristic. 
Copyright @ National Academy of Forensic Engineers (NAFE) http://www.nafe.org. Redistribution or resale is illegal. Originally published in the Journal of the NAFE volume indicated on the cover page. ISSN: 2379-3252

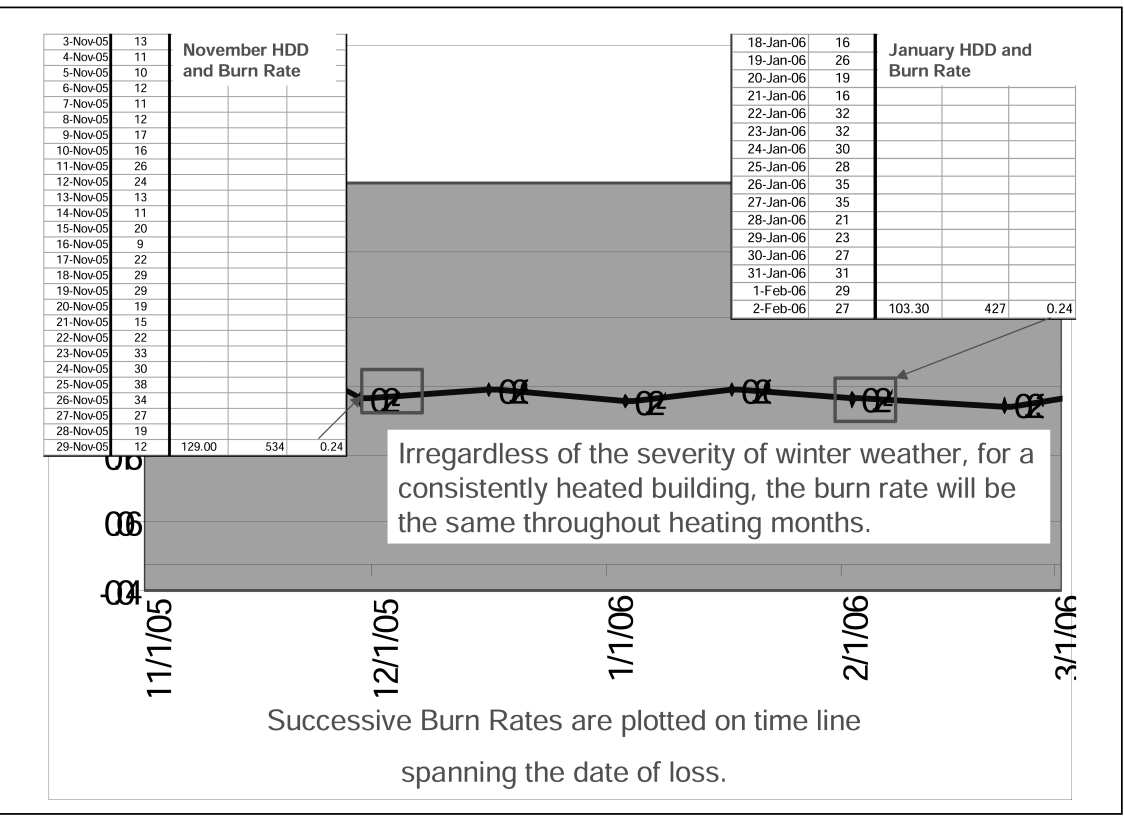

BURN RATE OVER TIME

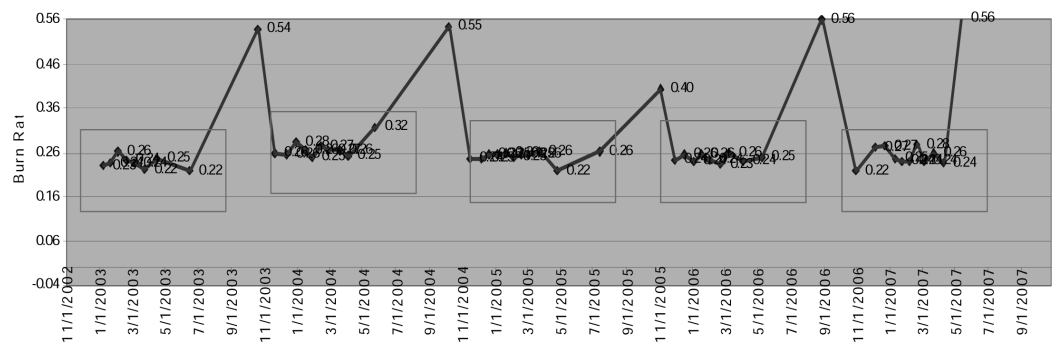

When Burn Rates are plotted over time, a consistent pattern showing a buildings winter fuel consumption requirement becomes evident.

Variations in this pattern can identify changes in heating system operation 
Copyright @ National Academy of Forensic Engineers (NAFE) http://www.nafe.org. Redistribution or resale is illegal. Originally published in the Journal of the NAFE volume indicated on the cover page. ISSN: 2379-3252

PAGE 64

JUNE 2008

NAFE 708F

\section{Graph Interpretation}

In the event of a sudden mechanical breakdown, the burn rate will fall suddenly from its normal heating level plateau.

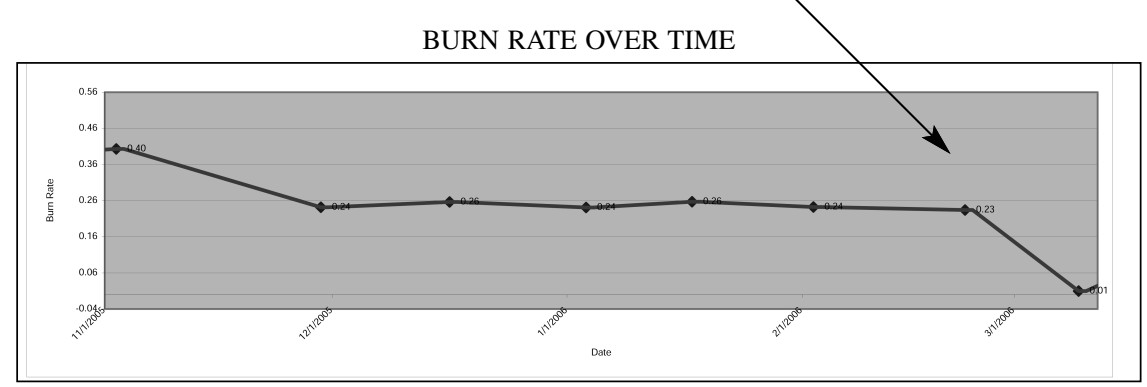

A condition of excessive thermostat setback will show a similar flat plateau, however, of a decreased level in comparison to previous winters when freeze damage did not occur at the property and heat is assumed to have been maintained.

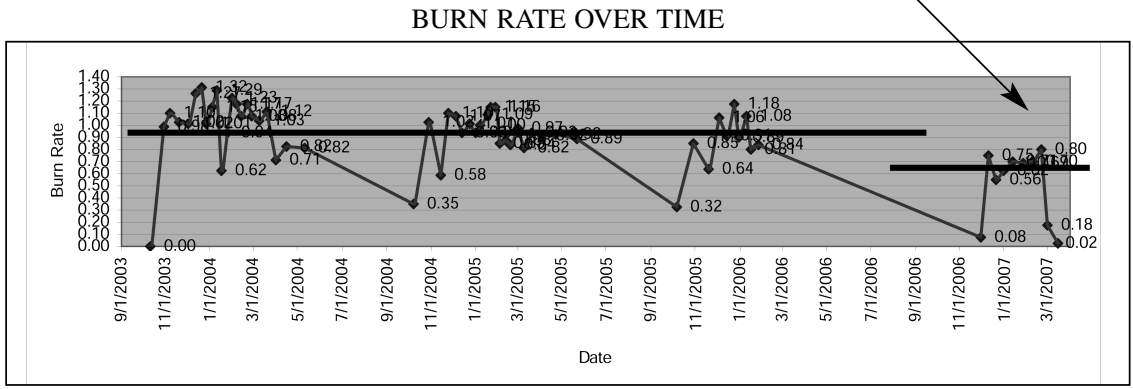

According to the 1997 Department of Energy's Residential Energy Consumption Survey, the following fuel savings can be obtained for every degree Fahrenheit of thermostat reduction.

Natural Gas 5\%

Electricity $6 \%$

Fuel Oil 4\%

Kerosene 5\%

LP Gas 5\%

By applying previous burn rates (when the building did not suffer freeze damage) and applying the fuel savings percentages per degree of thermostat setback, a calculation of the new thermostat setting at the time of loss can be approximated. 
A residential thermostat is essentially off at temperatures below 40 degrees. If an excessive thermostat setback calculation identifies a thermostat to have been in this low range the system could also have been turned off.

It should also be noted, however, that this calculation method applies to single thermostat heating systems. Unless all thermostats in a multi-zoned house were turned to the same low setting, this method cannot identify the setback temperature of one thermostat.

\section{Date of Tank Run out or System Shutdown}

By measuring the amount of oil or recording the amount of fuel in an LP gas tank during your inspection (provided that the system has not been put back into operation by that time) by using the amount of accumulated heating degree days between deliveries, as well as the burn rate, a date of run out or shutdown can easily be calculated.

This is done by taking the building's demonstrated burn rate's reciprocal (or K Factor in units of HDD/Fuel Units) and multiplying it against the fuel burned since the last tank fill or meter reading. Cancellation of units provides how many heating degrees of fuel were consumed.

Using this sum of heating degree-days and subtracting the weather data provided daily heating degree-days from the last delivery prior to the loss, the day of equipment shutdown can be calculated.

In closing, a graphical analysis method of fuel usage practices provides an accurate and visual representation of the buildings fuel usage requirements and trends that can more easily be communicated to and understood by a layperson, i.e. a juror.

A fuel usage analysis that is based upon the building's demonstrated need for fuel is indisputable in that past fuel usage levels establishes a fuel usage baseline indicative of a functioning heating system for that particular home.

From this baseline, variations can be identified and analyzed to help identify the cause of the loss.

A final benefit of a fuel usage analysis is the ability to identify the presence of a fuel leak.

An unexplained increase in the burn rate without any possibility of the thermostats being turned up or the building envelope being opened (such as an opened door or window being left open) can indicate a leak within the fuel system. 
Copyright @ National Academy of Forensic Engineers (NAFE) http://www.nafe.org. Redistribution or resale is illegal. Originally published in the Journal of the NAFE volume indicated on the cover page. ISSN: 2379-3252

\section{CASE STUDIES}

\section{Case Study No. 1 Failure To Provide Adequate Fuel}

In this case that went to trial, the home was purchased on November 27, 2002. For the following weeks throughout the winter of 2002/2003, the house was being renovated and not occupied as a full time residence, being checked once a week.

The homeowner was not on an automatic delivery program with any local oil company.

Reportedly, on 7 December 2002, the 275 gallon oil tank was filled to its maximum capacity (which is usually about 255 gallons).

The house temperatures were said to be set in the 65 degree range.

Reportedly, on March 16, 2003, frozen pipes were found at the property and a local oil company reported that the customer had run out of oil, which the property owner denied.

BURN RATE OVER TIME

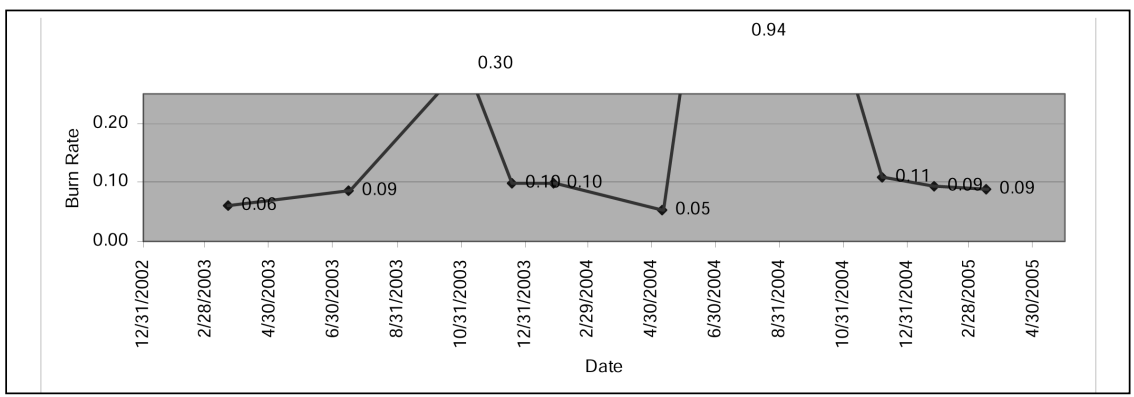

Although an extensive fuel history was not present for fuel consumed prior to the loss, fuel usage analysis of the home after the loss showed that in winter months, the home consumed fuel in the .10 Gallon/HDD range.

Applying this to the oil tank's report of being full of oil on December 7, 2002 , this would provide the home with enough oil to maintain a 65 degree temperature against 2,550 Heating Degree Days.

Subtracting daily heating degree days from this amount indicated that the tank would have run out on or about 14 February 2003, one month prior to the damage being discovered. 
Copyright () National Academy of Forensic Engineers (NAFE) http://www.nafe.org. Redistribution or resale is illegal. Originally published in the Journal of the NAFE volume indicated on the cover page. ISSN: 2379-3252

\section{Case Study No. 2 Heating Equipment Not Operational in Winter Months}

In this case this Cape Cod beach front vacation home was found to be damaged by frozen pipes on 15 January 2004 .

Negligence on the part of the homeowner in not maintaining heat at this property resulted in a denial of coverage and a lawsuit on the part of the homeowner against the insurance company.

\section{BURN RATE OVER TIME}

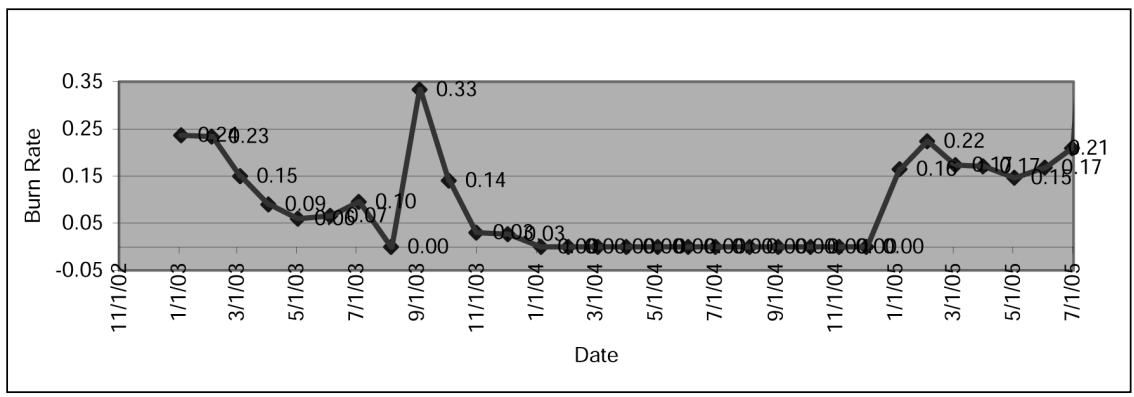

Fuel usage analysis showed that the burn rates achieved in subsequent winter months were in the .13 to .16 therms of fuel per heating degree day.

Prior to the loss, in late November 2003, the last burn rate was found to be .03 therms/heating degree day, which is identified as the natural gas consumed by appliance pilot flames or to maintain the temperature of a gas fired water heater not in use.

We concluded that the furnace never became operational after summer months and that condition did not change up to the time freezing temperatures arrived in the area in the late winter months of 2003 and early winter of 2004.

\section{Case Study No. 3 Improper Installation of Piping}

In the winter of 2003/2004, exceptionally bitterly cold temperatures were present in New England and many vacation homes on Cape Cod and the islands of Martha's Vineyard and Nantucket were damaged in unprecedented numbers.

In this newly constructed oceanfront home on one of Cape Cod's coastlines, heating system installers installed a water supply line to a humidifier to a warm air heating system component installed in the unheated attic.

This line froze causing hundreds of thousands of dollars in property damage. 
Copyright (C) National Academy of Forensic Engineers (NAFE) http://www.nafe.org. Redistribution or resale is illegal. Originally published in the Journal of the NAFE volume indicated on the cover page. ISSN: 2379-3252

PAGE 68

JUNE 2008

NAFE 708F

The attic was an unheated space and as such the water line was installed in violation of The Massachusetts and International Plumbing Codes.

Additionally, the water line was installed in violation of the manufacturer's instructions, as well.

Fuel usage analysis showed that heat was maintained and was supported by a diligent caretaker's schedule that resulted in daily examinations of this heated property.

Since fuel and heat were maintained throughout the winter months at this property, the sole

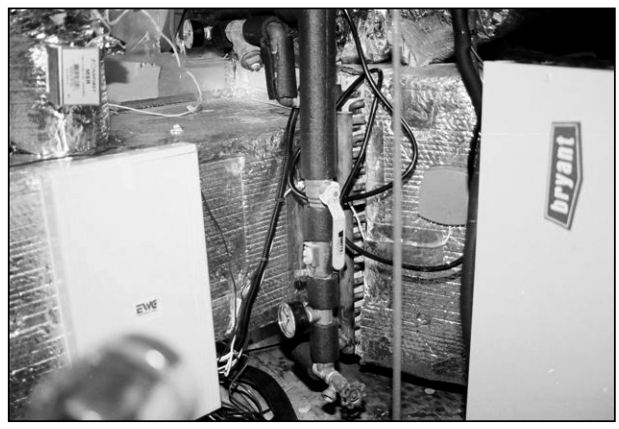
cause of this loss was attributed to the error in the location of the installation of this piping without any contributing factors.

\section{Conclusion, Putting It All Together}

The root causes of freezeup damage to a property have been identified as originating from four basic origins known as the "Blame Pie" of a heating system failure.

These are mechanical failure, piping and appliance installation errors, utility failure, and excessive thermostat setback.

By conducting a thorough site examination of the heating system appliance, be it a boiler or furnace, as well as the condition of the failed piping at these locations, physical evidence can provide information as to why the loss had occurred.

Often times, however, there may be conditions encountered where there is no identified failed component and no reasonable explanation for the failure.

It is possible that a heating system may have simply been shut down inadvertently by someone turning off a service switch to the appliance. This may have been done accidentally and unknowingly to anyone. 
Copyright @ National Academy of Forensic Engineers (NAFE) http://www.nafe.org. Redistribution or resale is illegal.

Originally published in the Journal of the NAFE volume indicated on the cover page. ISSN: 2379-3252

NAFE 708F

FREEZE DAMAGE TO BUILDINGS

PAGE 69

Although there may be instances where the exact cause of heating system failure may not be known, by performing a fuel usage analysis, the characteristics of fuel consumption can be evaluated to provide the most reasonable explanation of the loss.

By graphing the fuel usage analysis and identifying the trends of fuel consumption in years prior to the loss and just before the loss, it can be identified as to whether or not the loss occurred as a result of a sudden event such as mechanical breakdown or utility failure or if it was caused by conditions such as excessive thermostat setback.

In addition, fuel usage analysis can provide information identifying when a loss had occurred, which may coincide with other occurrences at the loss site, such as utility failure or contractor activity at the property.

By relying upon physical observations and reported testimony solely, misleading statements by property owners, careless professional property caretakers, or false "decoy" equipment failures planted by homeowners and heating contractors cannot be identified.

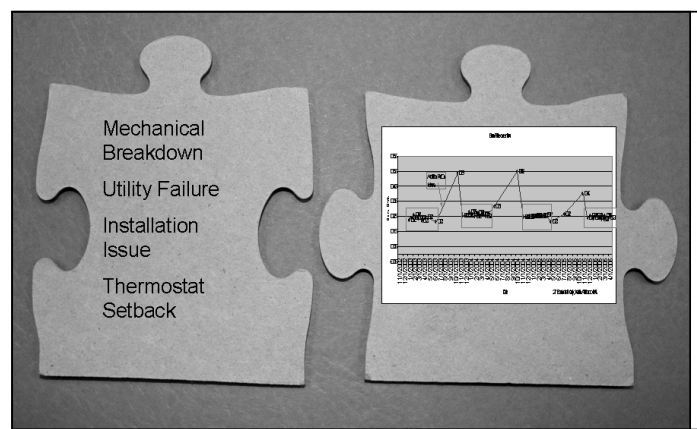

Field Findings and Reported Statements should match fuel usage analysis results

Fuel usage analysis provides an accurate and independent evaluation tool that provides a guideline as to what occurred at the property, independent of field observations, as well as reported statements.

A thorough forensic engineering field investigation, used in conjunction with an in-depth fuel usage analysis, can provide a level of accuracy that either analysis could not provide alone. 
Copyright $\odot$ National Academy of Forensic Engineers (NAFE) http://www.nafe.org. Redistribution or resale is illegal. Originally published in the Journal of the NAFE volume indicated on the cover page. ISSN: 2379-3252

\section{References}

1. Plick and Associates newsletter December 2005.

\section{Bibliography}

1. Security World News Article by Ralph Winn published 11/27/2007.

2. Plick and Associates newsletter December 2005.

3. American Society of Heating Refrigeration and Air Conditioning Engineers ASHRAE's Fundamental Handbook. 1791 Tullie Circle N.E. Atlanta GA 30329.

4. Handbook of Energy Audits, 6th Edition. Albert Thurmann P.E. C.E.M. and William Younger C.E.M. 2003 Fairmont Press Inc. 700 Indian Trail, Liburn, GA 30047

5. Audel's 1955 "Oil Burner Guide” By Frank D. Graham. Theo Audel \& Company Publishers 49 W. 23rd St, NY, NY.

6. 1997 United States Department of Energy's Residential Energy Consumption Survey. 1000 Independence Ave. SW Washington, DC

7. Methodology for Estimating Winter Energy Savings United States Department of Energy. 1000 Independence Ave. SW Washington, DC

8. International Code Council (ICC) International Plumbing Code. $4051 \mathrm{~W}$. Flossmoor Rd, Country Club Hills, IL 60478

9. International Code Council (ICC) International Mechanical Code. $4051 \mathrm{~W}$. Flossmoor Rd, Country Club Hills, IL 60478

10. International Code Council (ICC) International Energy Conservation Code. 4051 W. Flossmoor Rd, Country Club Hills, IL 60478

11. The Hydronics Institute division of GAMA's Residential Hydronic Heating System Guide 2000. PO Box 218 Berkley Heights NJ, 07922-0218

12. Experimental Determination of Pressure During Ice Expansion A.L. Vidovskii; UDC 531.328:531.787. Translated from Gidrotekhnicheskoe Stroitel'stvo, No. 8 pp. 46-47 August 1972.

13. Can hot water freeze faster than cold water? Monwhea Jeng (Mono) Department of Physics, University of California November 1998.

14. Charles Darwin "The Origin of Species, by Means of Natural Selection, or the Preservation of Favoured Races in the Struggle for Life". New American Library, Penguin Books Ltd. 80 Strand, London WC2R ORL, England. 
Copyright @ National Academy of Forensic Engineers (NAFE) http://www.nafe.org. Redistribution or resale is illegal. Originally published in the Journal of the NAFE volume indicated on the cover page. ISSN: 2379-3252

\section{Acknowledgements}

Lisa, Alec \& Max

Ron Lasko, Norm Lague, Richard Friedline of: Friedline \& Carter Insurance Adjusters, Hyannis, MA

Patrick Fiske, North Attleboro, MA

\section{Nomenclature}

Heating Degree Day (HDD)

Burn Rate - Fuel consumed in a building in units of fuel per HDD

K Factor - Fuel consumed in a building in units of HDD per unit of fuel consumed.

Boiler - Heating Appliance that uses water to transmit heat energy.

Furnace - Heating appliance that uses air to transmit heat energy.

BTU British Thermal Unit.

Natural Gas (approximately) 1 cubic foot $=1000$ BTU

$1 \mathrm{KWH}=3413 \mathrm{BTU}$

LP Gas 2516 BTU/Cubic Foot

LP Liquid $21591 \mathrm{BTU} / \mathrm{Lb}$

LP Liquid 91547 BTU/Gallon

Fuel Oil No. 1, 132,000 - 137,000 BTU/Gal

Fuel Oil No. 2, 137,000 - 141,800 BTU/Gal

Fuel Oil No. 4, 143,000 - 148,100 BTU/Gal

Fuel Oil No. 5 (Light) 146,000 - 150,000 BTU/Gal

Fuel Oil No. 5 (Heavy) 149,000 - 152,000 BTU/Gal

Fuel Oil No. 6 151,000 - 155,900 BTU/Gal 
Copyright @ National Academy of Forensic Engineers (NAFE) http://www.nafe.org. Redistribution or resale is illegal.

Originally published in the Journal of the NAFE volume indicated on the cover page. ISSN: 2379-3252

PAGE 72

JUNE 2008 